\title{
Cognitive remediation improves memory and psychosocial functioning in first-episode psychiatric out-patients
}

\author{
R. S. C. Lee ${ }^{1,2 *}$, M. A. Redoblado-Hodge ${ }^{3}$, S. L. Naismith ${ }^{1}$, D. F. Hermens ${ }^{1}$, M. A. Porter ${ }^{2}$ \\ and I. B. Hickie ${ }^{1}$ \\ ${ }^{1}$ Clinical Research Unit, Brain and Mind Research Institute, University of Sydney, Sydney, Australia \\ ${ }^{2}$ Department of Psychology, Macquarie University, Sydney, Australia \\ ${ }^{3}$ Child Development Unit, The Children's Hospital at Westmead, Sydney, Australia
}

Background. Cognitive remediation (CR) is an effective treatment for several psychiatric disorders. To date, there have been no published studies examining solely first-episode psychiatric cohorts, despite the merits demonstrated by early intervention CR studies. The current study aimed to assess the effectiveness of CR in patients with a firstepisode of either major depression or psychosis.

Method. Fifty-five patients (mean age $=22.8$ years, S.D. $=4.3$ ) were randomly assigned to either CR $(n=28)$ or treatment as usual (TAU; $n=27)$. CR involved once-weekly 2-h sessions for a total of 10 weeks. Patients were comprehensively assessed before and after treatment. Thirty-six patients completed the study, and analyses were conducted using an intent-to-treat (ITT) approach with all available data.

Results. In comparison to TAU, CR was associated with improved immediate learning and memory controlling for diagnosis and baseline differences. Similarly, CR patients demonstrated greater improvements than TAU patients in psychosocial functioning irrespective of diagnosis. Delayed learning and memory improvements mediated the effect of treatment on psychosocial functioning at a marginal level.

Conclusions. CR improves memory and psychosocial outcome in first-episode psychiatric out-patients for both depression and psychosis. Memory potentially mediated the functional gains observed. Future studies need to build on the current findings in larger samples using blinded allocation and should incorporate longitudinal follow-up and assessment of potential moderators (e.g. social cognition, self-efficacy) to examine sustainability and the precise mechanisms of CR effects respectively.

Received 5 April 2012; Revised 27 June 2012; Accepted 13 August 2012; First published online 14 December 2012

Key words: Cognitive remediation, depression, early intervention, neuropsychology, psychosis.

\section{Introduction}

Cognitive deficits are a clinically significant feature among psychiatric disorders and often, in some combination, persist into remission (Millan et al. 2012). In major depressive disorder (MDD; Jaeger et al. 2006; Withall et al. 2009) and schizophrenia (Green et al. 2004), impairments are longitudinally predictive of poor functional outcome. Furthermore, cognitive improvements following pharmacological (Keefe et al. 2007), neuropsychological (Fiszdon et al. 2008) and psychosocial (Brekke et al. 2009) interventions in schizophrenia are associated with functional improvements, highlighting the potential that

\footnotetext{
* Address for correspondence: Mr R. S. C. Lee, 100 Mallett Street, Brain and Mind Research Institute, Camperdown, NSW 2050, Australia.

(Email: sze.lee@sydney.edu.au)
}

targeting neuropsychological deficits has in reducing disability.

At present, psychiatric pharmacotherapies are largely ineffective in ameliorating persisting cognitive deficits (Goldberg et al. 2007). By contrast, cognitive rehabilitation seems to be more promising. Initial studies used operant conditioning procedures in improving behavioural performance (Cohen, 1956; Wagner, 1968). A second wave of studies in the early 1990s brought together a range of techniques under the collective term 'cognitive remediation' (CR). CR programmes are highly heterogeneous, differing on whether they consist of 'drill-and-practice' or compensatory strategy learning, therapist facilitation, computer training, or the length and intensity of treatment. Various structured programmes have codified combinations of these approaches, including the Neuropsychological and Educational Approach to Remediation (NEAR; Medalia et al. 2002).

The online version of this article is published within an Open Access environment subject to the conditions of the Creative Commons Attribution-NonCommercial-ShareAlike licence <http://creativecommons.org/licenses/by-nc-sa/2.5/ $>$. The written permission of Cambridge University Press must be obtained for commercial re-use. 
The efficacy of CR has been well established in chronic schizophrenia (Wykes et al. 2011). Neuropsychological functioning seems to benefit most from $\mathrm{CR}$ with mean effect sizes typically in the medium range (Medalia \& Choi, 2009). Smaller effects are observed for functional improvements, which are reported to be mediated by gains in memory and executive functioning (Wykes et al. 2007; Fiszdon et al. 2008). Recently, CR has been successfully applied to a range of other psychiatric disorders, including MDD (Elgamal et al. 2007; Naismith et al. 2010b, 2011), bipolar disorder (Deckersbach et al. 2010), anorexia nervosa (Wood et al. 2011), obsessive-compulsive disorder (Buhlmann et al. 2006) and substance use disorders (Bickel et al. 2011). Perhaps the basis for a potential 'cross-diagnostic' utility of CR is its focus on cognitive deficits readily found in psychiatric illnesses. Indeed, a recent study found that CR effectiveness was unrelated to diagnosis in schizophreniaspectrum disorders (Lewandowski et al. 2011). The enthusiasm for cross-diagnostic implementation is reflected in studies using mixed psychiatric samples (Choi \& Medalia, 2005; Naismith et al. 2010a). Pragmatically, a cross-diagnostic implementation may prove to be more cost-effective in mental health clinics that are not constrained by diagnostic groupings. Indeed, this approach is particularly appropriate for younger patients in the early stages of psychiatric disease, where the longitudinal trajectory is not yet evident (McGorry et al. 2006; Hickie et al. 2012).

CR studies have generally focused on later stages of psychiatric illness (cf. Wykes et al. 2007). By contrast, identification and treatment at earlier stages are crucial, given the cumulative effects of mental disorders (McGorry et al. 2006; Hetrick et al. 2008), which are underscored by findings that longer durations of untreated illness are associated with structural brain abnormalities in MDD (Sheline et al. 2003) and schizophrenia (Lappin et al. 2006; Malla et al. 2011), and neuropsychological deterioration (Amminger et al. 2002; Lappin et al. 2007; Gaynor et al. 2009). Early intervention studies have largely focused on pharmacological (Kahn et al. 2008) and cognitive behavioural (Lynch et al. 2010) therapies, which typically affect state-dependent cognitive function but have little effect on pre-existing or persisting cognitive impairments. This is despite evidence demonstrating prominent memory deficits in emerging MDD (Naismith et al., unpublished observations) and prodromal psychosis (Fusar-Poli et al. 2012), and broader neuropsychological dysfunction in first-episode MDD and schizophrenia across multiple cognitive domains (Mesholam-Gately et al. 2009; Lee et al. 2012). Taken together with findings that impairments seem to be related to higher rates of relapse and recurrence (Majer et al. 2004), the early treatment of persisting cognitive impairment may prove to be an important step in reducing the everyday impact and chronicity of mental disorders. To this end, several studies have demonstrated the effectiveness of $\mathrm{CR}$ in improving neurocognition in early-onset adolescents with psychosis (Ueland \& Rund, 2004, 2005; Wykes et al. 2007), and also in combination with functional gains and neuroprotection in 'early-course' schizophrenia (Eack et al. 2009, 2010). There are also two CR trials currently being conducted in first-episode psychosis (Breitborde et al. 2011; Vesterager et al. 2011). To the best of our knowledge, there have been no published studies demonstrating the effectiveness of CR in solely firstepisode psychiatric patients.

The paucity of early intervention studies is surprising given evidence suggesting that $C R$ programmes at earlier stages of schizophrenia (Gupta et al. 2011) and at younger ages (Wykes et al. 2009) are associated with greater cognitive and functional gains. Conversely, CR at more chronic stages and older ages may yield poorer outcomes (Dickinson et al. 2010). Clearly, there is sufficient theoretical impetus behind investigating $\mathrm{CR}$ in the early stages of major psychiatric illnesses. To this end, the NEAR programme may be particularly well suited. NEAR uses both drill-and-practice and compensatory approaches, and is based on theories of how people learn best (Medalia \& Freilich, 2008). Principles such as errorless learning, positive reinforcement and shaping help to guide therapists in promoting behavioural change. Of particular relevance to early intervention, NEAR has been shown to be effective in a mixed sample including first-episode schizophrenia patients (Redoblado-Hodge et al. 2010), and in a relatively young sample of MDD patients (Naismith et al. 2010b). Additionally, a structured psycho-education programme may be an important adjunct, and has recently been demonstrated to be effective in late-life depression (Naismith et al. 2011). Psycho-education is primarily aimed at improving awareness of cognitive deficits, and is reported to improve insight in early schizophrenia (Ruzanna et al. 2010). Facilitating awareness is pivotal, given that insight is commonly limited in both MDD (Yen et al. 2005) and schizophrenia (Medalia \& Thysen, 2008), with downstream effects on motivation (Markland et al. 2005), a crucial factor in CR success (Medalia \& Saperstein, 2011). Indeed, it is also difficult to see how patients would benefit from CR if they do not understand the reasons for treatment and the precise cognitive functions being targeted.

Overall, the aim of the current study was to examine the clinical effectiveness of NEAR in out-patients diagnosed with first-episode MDD or psychosis, two of the most common presenting disorders in our youth 
mental health clinics (Scott et al. 2009, 2012). These disorders were chosen on the basis that cognitive impairments are common in both, and have been shown to respond to CR. Two primary hypotheses were postulated. First, CR patients were expected to demonstrate greater gains in cognitive and psychosocial functioning than a treatment-as-usual (TAU) cohort, which was included to control for practice effects (Goldberg et al. 2010) and the effects of ongoing psychosocial and pharmacological treatment (Keefe et al. 2007; Brekke et al. 2009). Second, greater cognitive and functional gains were expected in the CR group even while controlling for diagnosis to demonstrate the cross-diagnostic utility of CR. A further aim of the current study was to determine whether functional improvements would be mediated by improvement in memory and executive functioning, consistent with the literature.

\section{Method \\ Subjects}

The study was conducted at the Brain and Mind Research Institute (BMRI), Sydney, Australia. Consecutive referrals were obtained from clinicians in affiliated out-patient clinics (Headspace Central Sydney; The Clinical Centre, BMRI; Community Mental Health Services, NSW Health). Patients were included if they met the following inclusion criteria: (1) a lifetime history of a single episode of MDD or a psychotic disorder according to DSM-IV-TR (APA, 2000); (2) clinically stable as determined by a treating psychiatrist; and (3) fluent in English.

Participants were excluded if they: (i) were currently diagnosed with substance dependence, a developmental disorder or a neurological condition; (ii) had a history of traumatic brain injury; (iii) were currently prescribed a first-generation antipsychotic medication; (iv) had an estimated pre-morbid intelligence quotient (IQ) of $<80$; or (v) did not demonstrate significant cognitive dysfunction as defined by a neuropsychological test score of at least 1.5 standard deviations (S.D.) below their predicted pre-morbid IQ (Lezak et al. 2012). This criterion was chosen to prevent ceiling effects in the primary outcome measures, and from clinical experience, which has demonstrated that most patients with severe mental illnesses meet this criteria. Indeed, in a large sample of healthy adults, Schretlen et al. (2003) found that the average person had at least one neuropsychological test score falling 1.9 S.D. below their predicted pre-morbid IQ, across a comprehensive neuropsychological battery not dissimilar from the current study. Thus, including those with milder deficits may erroneously include patients not cognitively impaired as a result of psychiatric morbidity, but normal intra-individual variability.

Written informed consent was obtained from all participants. The current study was approved by the Human Research Ethics Committees of the University of Sydney and Macquarie University.

\section{Design}

Following referral and screening, participants were block randomized to either CR or TAU (see Fig. 1). Neither clinicians (raters and therapists) nor participants were blinded to allocation. Participants were initially assessed on a range of measures, and subsequently commenced either a 10 -week period of CR while still receiving TAU or continued to receive TAU (only) for the same period. Patients were reassessed using the same measures at follow-up.

\section{Measures}

All participants were assessed by the first author (R.S.C.L.). At baseline, clinical and demographic information was ascertained through an interview. Two measures were also administered to estimate premorbid ability: the Wechsler Test of Adult Reading (WTAR; Wechsler, 2001) and Information (Wechsler, 1997a). Baseline and follow-up assessments included clinical, neuropsychological and functional measures. Clinical measures included the total score on the 17item Hamilton Depression Rating Scale (HAMD-17; Hamilton, 1960) and on the Brief Psychiatric Rating Scale-Expanded (BPRS-E; Ventura et al. 1993). Primary outcomes included several cognitive and functional measures. Neuropsychological tests were organized into five theoretically derived cognitive domains (Lezak et al. 2012). 'Processing Speed' was measured using the Trail Making Test - Part A (TMTA ; Franzen et al. 1990) and Category Fluency (Spreen \& Benton, 1977). 'Attention and Working Memory' was assessed using Longest Digit Span Forward and Longest Digit Span Backward (LDSF and LDSB; Wechsler, 1997a), Spatial Span length (Cambridge Neuropsychological Test Automated Battery, CANTAB; www.camcog.com), Rapid Visual Processing Hits score (RVP Hits; CANTAB), and Mental Control (Wechsler, 1997b). 'Immediate Learning and Memory' was measured using Logical Memory I (Wechsler, 1997b), Rey Auditory Verbal Learning Test total score (RAVLT Total; Taylor, 1959) and Paired Associates Learning (PAL; CANTAB). 'Delayed Learning and Memory' was assessed using Logical Memory II Percentage Retention (LM Retention; Wechsler, 1997b), RAVLT 20-Minute Percentage Retention (RAVLT Retention; Taylor, 1959) 


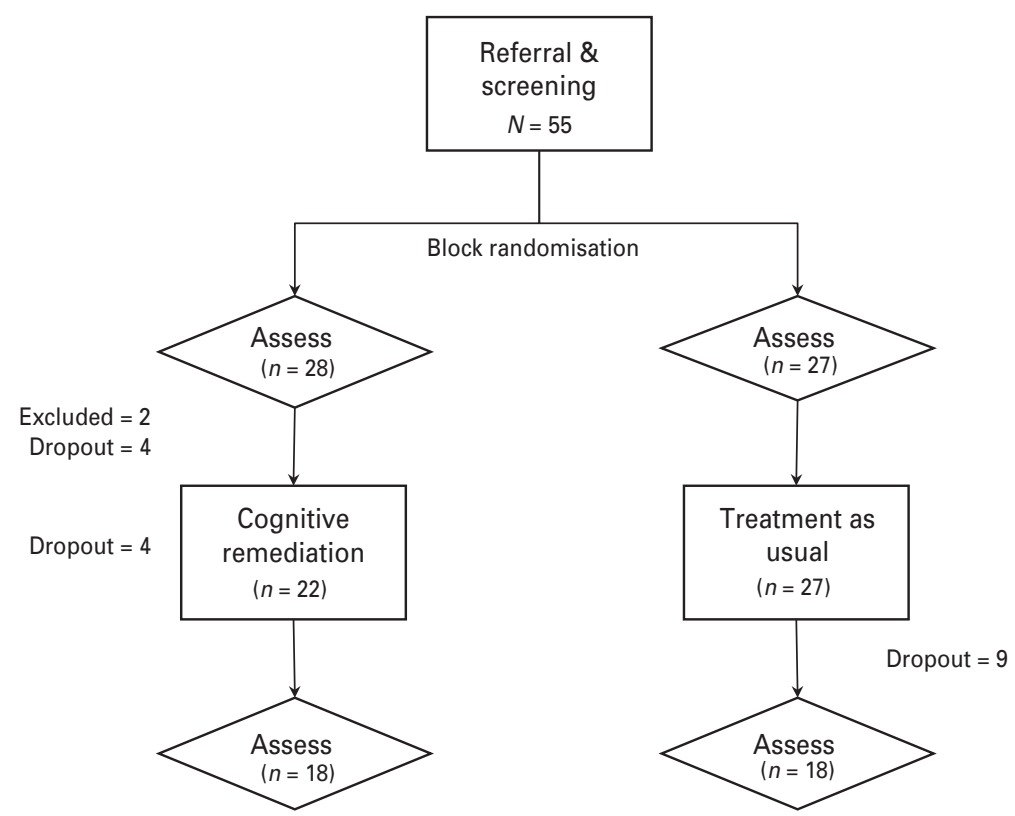

Fig. 1. Flowchart of study design.

and Rey-Osterrieth Complex Figure 3-Minute Recall (CFT 3min; Corwin \& Bylsma, 1993). 'Executive Functioning' was indexed by TMT - Part B (TMT-B; Franzen et al. 1990), Intra/Extradimensional Set Shift Errors (IED Errors; CANTAB) and Letter Fluency (FAS; Spreen \& Benton, 1977). Alternate forms were used at follow-up where available (Reitan \& Wolfson, 1985; Crawford et al. 1989; Hubley \& Tremblay, 2002). Scores were standardized into $z$ scores based on demographically adjusted norms from internal (Wechsler, 1997a, b, CANTAB) and external samples (Meyers \& Meyers, 1995, 1996; Tombaugh et al. 1996, 1999; Rickert \& Senior, 1998). Functional outcome was assessed using the standardized total score of the Social Functioning Scale (SFS; mean $=100$, S.D. $=15$; Birchwood et al. 1990). A higher score on neuropsychological and functional measures indicated more superior functioning.

\section{Intervention}

The NEAR CR programme involved once-weekly 2-h sessions for a total of 10 weeks, and was adapted to include a psycho-education component (Medalia \& Freilich, 2008). Each session started with psychoeducation regarding cognitive deficits and relevant compensatory strategies adapted from a previously implemented programme in the elderly (Naismith et al. 2011). Patients also received a bound workbook of PowerPoint slides. The talks were given by either the therapist facilitating the groups (R.S.C.L.) or invited guest speakers with expertise in the area of interest. Following psycho-education, patients engaged in therapist-led drill-and-practice group activities, and computer-assisted cognitive training using a range of software programs that were educational, designed to target cognitive deficits in the laboratory and/or available online. The cognitive training component was specifically tailored to each individual's neuropsychological profile. Patients were encouraged throughout the program to experiment with compensatory strategies during warm-up activities, computer training, and in their own time outside the clinic.

All patients also received TAU care, involving ongoing monitoring by a psychiatrist of symptoms and medication use, in addition to case management by mental health clinicians. Participants were not concurrently involved in structured cognitive (e.g. social cognitive remediation) or psychosocial (e.g. social skills training) rehabilitative interventions at any time during the study.

\section{Data analysis}

IBM SPSS version 20.0 (SPSS Inc., USA) was used for all statistical analyses. Neuropsychological standardized scores were reduced to five composite scores by averaging $z$ scores from each cognitive domain (Lezak et al. 2012). Composite scores were used instead of individual test scores because the latter are less reliable (Salthouse, 2012) and unnecessarily inflate the type I error rate. Analyses were conducted using all available data excluding those from participants who did not meet entry criteria. Thus, an intent-to-treat (ITT) approach was adopted, assuming data were missing 
at random (MAR), including any significant predictors of drop-out as covariates, consistent with previous research (Wykes et al. 2012). One-way ANOVAs were conducted to determine: (1) whether those who withdrew from the study were different from those who completed the study; and (2) whether any baseline variable differed between treatment conditions despite randomization. Any differences at baseline were also included as covariates in subsequent and respective primary outcome analyses. Repeatedmeasures ANOVAs were conducted on symptomatology (HAMD-17 and BPRS-E) and medication-use variables to ensure primary outcome analyses were not confounded by symptom or medication change. Primary outcomes were analysed using ANOVAs for each cognitive composite and psychosocial functioning, with treatment condition as the between-subjects factor. Subsequently, ANCOVAs were conducted to include any predictors of drop-out, baseline differences and diagnosis as covariates. If functional change was significantly improved in CR compared to TAU, it was regressed on treatment condition and each separate cognitive change score to determine whether cognitive improvement predicted functional improvement over and above the direct effects of treatment. For the primary cognitive outcomes based on Bonferroni adjustments for multiple comparisons, $\alpha$ was set at 0.01 . For all other statistical inferences, $\alpha$ was set at 0.05 .

\section{Results}

In total, 55 participants were recruited and assessed at baseline. Two participants were excluded from further participation because of inadequate English or borderline impaired pre-morbid IQ $(<80)$. In addition, 17 participants dropped out prior to completing the study because of hospitalization for relapse $(n=3)$, work commitments $(n=3)$ or disinterest $(n=11)$. In total, 36 participants completed the whole study, with seven and 11 first-episode depression and psychosis patients in each condition respectively. There was no differential drop-out rate between conditions ( $p>0.05)$, and those who dropped out did not differ from those who completed the study on any demographic or clinical variables, medication use, neuropsychological or psychosocial functioning $(p>0.05)$. The test-retest interval averaged 21 and 19 weeks for $\mathrm{CR}$ and TAU participants respectively $(p>0.05)$.

\section{Baseline differences}

Baseline sample characteristics are displayed in Table 1, and stratified according to treatment condition and diagnosis. Participants were relatively young (mean age $=22.8$ years, S.D. $=4.3$, range $16-34$ ) and well educated $($ mean $=12.6$ years, S.D. $=2.1$, range 9-18). There were no significant differences between treatment conditions on any baseline sample characteristics, including the primary functional outcome $(p>0.05)$. However, in terms of diagnosis, firstepisode psychosis patients had a significantly later age of onset $\left(F_{1,47}=7.08, p<0.05\right)$ and lower predicted IQ $\left(F_{1,50}=6.33, p<0.05\right)$, were less depressed $\left(F_{1,51}=8.23\right.$, $p<0.01)$, had a greater proportion using medication $\left(\chi_{1,53}^{2}=12.07, p<0.001\right)$ and antipsychotics $\left(\chi_{1,53}^{2}=27.65\right.$, $p<0.001)$, and also a higher mean haloperidol dose equivalency $\left(F_{1,37}=11.04, p<0.01\right)$.

CR participants also performed significantly worse than TAU participants in attention and working memory at baseline $\left(F_{1,47}=4.06, p=0.05\right)$. No other cognitive domains were significantly different between conditions $(p>0.05)$. Diagnostically, firstepisode psychosis patients performed significantly more poorly than depressed patients on every cognitive composite score ( $p<0.005$; see Fig. 2).

\section{Primary outcomes}

There were no differential changes to psychiatric symptoms or medication dosage between groups ( $p>0.05)$, or changes to the type of medication(s) prescribed between assessments.

Repeated-measures ANOVA for the primary cognitive composite scores indicated that $\mathrm{CR}$ patients improved significantly more than TAU patients on attention and working memory $\left(F_{1,34}=8.10, p<0.01\right.$; see Table 2) and immediate learning and memory $\left(F_{1,34}=15.51, p<0.001\right)$. Controlling for diagnosis and baseline attention and working memory using repeated-measures ANCOVA, only immediate learning and memory remained significant $\left(F_{1,32}=7.47\right.$, $p<0.01)$. Specifically, CR independently contributed to $18.9 \%$ of the variance in immediate learning and memory improvement, which is considered a relatively large effect according to Cohen's criteria (1988). No other repeated-measures ANCOVA interactions by group were significant $(p>0.05)$.

With regard to psychosocial functioning, controlling for diagnosis, CR patients demonstrated significantly greater improvement than TAU patients on the SFS $\left(F_{1,32}=5.64, p=<0.05\right)$. The effect size of relative functional gain in CR patients was large, with treatment accounting for $14.6 \%$ of the variability in improvement.

\section{Mediation models}

Controlling for the effects of treatment $(\beta=0.30$, $\left.t_{33}=1.91, p=0.07\right)$, improvement in delayed learning 
Table 1. Sample characteristics of intent-to-treat (ITT) participants at baseline

\begin{tabular}{|c|c|c|c|c|c|c|}
\hline & $\mathrm{CR}(n=26)$ & TAU $(n=27)$ & Difference $\left(F / \chi^{2}\right)$ & First-episode depression $(n=20)$ & First-episode psychosis $(n=33)$ & Difference $\left(F / \chi^{2}\right)$ \\
\hline \multicolumn{7}{|l|}{ Sample } \\
\hline Male: Female & $12: 14$ & $16: 11$ & N.S. & $8: 12$ & $20: 13$ & N.s. \\
\hline First-episode depression & $10(38.5)$ & $10(37.0)$ & N.S. & - & - & - \\
\hline First-episode psychosis & $16(61.5)$ & $17(63.0)$ & N.S. & - & - & - \\
\hline \multicolumn{7}{|l|}{ Demographic characteristics } \\
\hline Age (years) & $22.88 \pm 4.0$ & $22.74 \pm 4.7$ & N.S. & $22.00 \pm 4.9$ & $23.30 \pm 3.9$ & N.S. \\
\hline Age of onset (years) & $19.00 \pm 3.9$ & $18.08 \pm 4.7$ & N.S. & $16.41 \pm 2.9$ & $19.66 \pm 4.5$ & $7.08^{*}$ \\
\hline Years of education & $12.46 \pm 1.8$ & $12.63 \pm 2.3$ & N.S. & $12.45 \pm 1.7$ & $12.61 \pm 2.3$ & N.S. \\
\hline Predicted $\mathrm{IQ}^{\mathrm{a}}$ & $100.85 \pm 9.4$ & $104.31 \pm 7.0$ & N.S. & $106.10 \pm 7.1$ & $100.38 \pm 8.5$ & $6.33^{*}$ \\
\hline General knowledge ( $z$ score $)^{\mathrm{b}}$ & $0.58 \pm 1.0$ & $0.81 \pm 0.8$ & N.S. & $0.93 \pm 0.9$ & $0.56 \pm 0.9$ & N.S. \\
\hline \multicolumn{7}{|l|}{ Clinical characteristics } \\
\hline HAMD-17 & $10.65 \pm 6.4$ & $8.59 \pm 6.6$ & N.s. & $12.70 \pm 7.5$ & $7.73 \pm 5.1$ & $8.23^{* *}$ \\
\hline BPRS-E & $37.35 \pm 7.6$ & $35.70 \pm 10.4$ & N.S. & $35.55 \pm 7.6$ & $37.09 \pm 9.9$ & N.S. \\
\hline SFS-Total & $106.89 \pm 7.6$ & $108.71 \pm 6.9$ & N.S. & $108.69 \pm 5.4$ & $107.29 \pm 8.2$ & N.s. \\
\hline \multicolumn{7}{|l|}{ Medication use } \\
\hline Medications & $22(84.6)$ & $22(81.5)$ & N.S. & $12(60.0)$ & $32(97.0)$ & $12.07^{* * *}$ \\
\hline Antidepressants & $10(38.5)$ & $10(37.0)$ & N.S. & $9(45.0)$ & $11(33.3)$ & N.S. \\
\hline Antipsychotics & $15(57.7)$ & $17(63.0)$ & N.S. & $3(15.0)$ & $29(87.9)$ & $27.65^{* * *}$ \\
\hline Haloperidol dose equivalence $(\mathrm{mg})^{\mathrm{c}}$ & $3.28 \pm 3.1$ & $4.18 \pm 3.1$ & N.s. & $0.83 \pm 1.2$ & $4.46 \pm 3.0$ & $11.04^{* *}$ \\
\hline Benztropine dose equivalence $(\mathrm{mg})^{\mathrm{d}}$ & $4.35 \pm 14.6$ & $4.50 \pm 15.4$ & N.s. & $0.07 \pm 0.1$ & $6.19 \pm 17.4$ & N.S. \\
\hline
\end{tabular}

CR, Cognitive remediation; TAU, treatment as usual; HAMD-17, 17-item Hamilton Depression Rating Scale; BPRS-E, Brief Psychiatric Rating Scale - Expanded;

SFS, Social Functioning Scale; N.s., not significant.

Values given as $n(\%)$ or mean \pm S.D.

${ }^{a}$ Wechsler (2001).

${ }^{\mathrm{b}}$ Information subtest (Wechsler, 1997a).

c Based on conversion table in Kane et al. (2003).

${ }^{\mathrm{d}}$ Based on conversion table in Minzenberg et al. (2004).

${ }^{*} p \leqslant 0.05,{ }^{* *} p \leqslant 0.01, * * * p \leqslant 0.001$. 


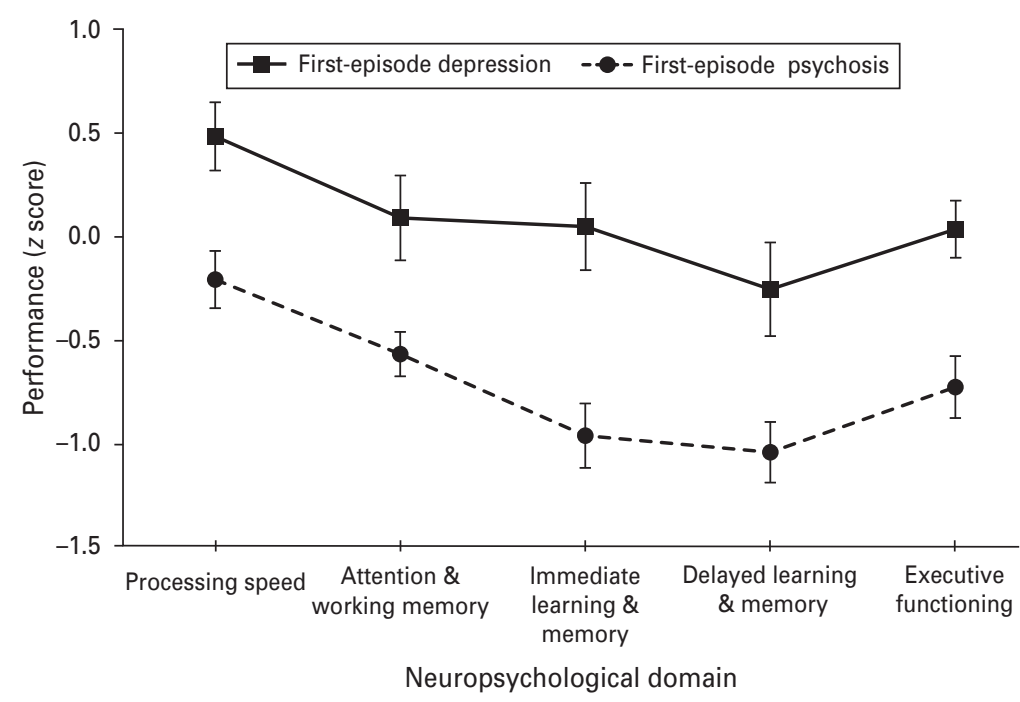

Fig. 2. Neuropsychological profile ( $z$ scores and standard errors) of cognitive composite scores according to diagnosis.

and memory independently predicted psychosocial gains at the trend level $\left(\beta=0.29, t_{33}=1.86, p=0.07\right)$. The overall model was significant $\left(R^{2}=0.21, F_{2,33}=\right.$ $4.38, p<0.05)$. No other changes to cognition were predictive of psychosocial improvement over and above treatment.

\section{Discussion}

Our results suggest that the neuropsychological profiles of patients recruited into the current study were largely consistent with those seen in larger samples with similarly young (Hermens et al., unpublished observations) and first-episode (Mesholam-Gately et al. 2009; Lee et al. 2012) cohorts. Pre-morbid intellectual functioning and educational attainment in our sample were generally fairly high. Neuropsychological functioning was most reduced in the learning and memory domains, consistent with studies demonstrating verbal learning and memory as most impaired in average to high IQ first-episode psychosis patients (Leeson et al. 2011), and highly educated early-episode youth with severe mental illnesses (Hermens et al., unpublished observations). In addition to memory, all other cognitive domains were significantly more reduced in patients with psychosis compared to those with only depression, in keeping with the literature (Schatzberg et al. 2000). Overall, the current sample is representative of those experiencing a first episode of MDD and psychosis.

The primary aim of the current study was to determine the effectiveness of $\mathrm{CR}$ as an early intervention in first-episode depressive and psychotic disorders. A modified NEAR programme was implemented in young out-patients, involving once-weekly cognitive training and psycho-education groups for a total of 10 weeks. The results suggest that CR is effective in improving immediate learning and memory. The effect size was large, and not inconsistent with older MDD patients (Naismith et al. 2010b, 2011), and greater than those found previously in chronic schizophrenia cohorts (Wykes et al. 2011). The larger effects currently observed may be suggestive of more favourable responses to neuropsychological intervention when implemented in the early stages of mental illness. The results are also consistent with findings that verbal learning and memory benefit most from $\mathrm{CR}$ in a young mixed psychiatric sample (Naismith et al. 2010a).

Importantly, CR as an early intervention also seems to be effective in improving psychosocial functioning. Effect size was again in the large range, and generally greater than identified in previous studies in chronic schizophrenia (Medalia \& Choi, 2009), and contrary to findings in more chronic MDD cohorts, which have largely failed to detect functional improvements (Naismith et al. 2010b, 2011). This discrepancy may be again indicative of a better treatment response when $C R$ is implemented at earlier stages of mental illness.

Secondary to our primary outcome analyses, regression modelling suggested that improved delayed learning and memory mediated the effect of $C R$ on psychosocial improvements. The overall model was significant and explained $21 \%$ of the variance in functional change. This was found despite a non-significant primary outcome analysis for this domain, which may suggest that the latter was underpowered, particularly given the inclusion of diagnosis and baseline attention and working memory as covariates with the currently modest sample size. The regression model is in keeping with previous findings 
Table 2. Mean scores ( \pm standard deviation) for each composite neuropsychological measure and functional outcome stratified by treatment condition and time

\begin{tabular}{|c|c|c|c|c|c|c|c|}
\hline \multirow[b]{2}{*}{ Domain } & \multicolumn{2}{|c|}{ Cognitive remediation $(\mathrm{CR})$} & \multicolumn{2}{|c|}{ Treatment as usual (TAU) } & \multicolumn{3}{|c|}{ Interaction $^{\mathrm{a}}$} \\
\hline & Pre-CR & Post-CR & Pre-TAU & Post-TAU & $F$ & $p$ & Partial $\eta^{2}$ \\
\hline \multicolumn{8}{|c|}{ Cognitive domain composite score } \\
\hline Processing speed & $-0.16 \pm 0.9$ & $0.06 \pm 0.8$ & $0.26 \pm 0.8$ & $0.12 \pm 0.9$ & 0.42 & 0.52 & 0.01 \\
\hline $\begin{array}{l}\text { Attention and working } \\
\text { memory }\end{array}$ & $-0.53 \pm 0.8$ & $0.05 \pm 0.7$ & $-0.08 \pm 0.7$ & $0.12 \pm 0.8$ & 3.07 & 0.09 & 0.09 \\
\hline $\begin{array}{l}\text { Immediate learning and } \\
\text { memory }\end{array}$ & $-0.76 \pm 1.1$ & $-0.18 \pm 1.0$ & $-0.41 \pm 0.9$ & $-0.44 \pm 1.1$ & 7.47 & $0.01^{* *}$ & 0.19 \\
\hline $\begin{array}{l}\text { Delayed learning and } \\
\text { memory }\end{array}$ & $-0.84 \pm 1.1$ & $-0.40 \pm 1.1$ & $-0.66 \pm 0.8$ & $-0.54 \pm 1.2$ & 0.38 & 0.54 & 0.01 \\
\hline Executive functioning & $-0.56 \pm 1.0$ & $-0.39 \pm 0.9$ & $-0.32 \pm 0.7$ & $-0.31 \pm 0.8$ & 0.00 & 0.98 & 0.00 \\
\hline \multicolumn{8}{|l|}{ Functional outcome } \\
\hline Social Functioning Scale (SFS) & $106.9 \pm 7.6$ & $111.9 \pm 6.7$ & $108.7 \pm 6.9$ & $110.4 \pm 7.6$ & 5.64 & $0.02^{*}$ & 0.15 \\
\hline
\end{tabular}

a ANCOVA with diagnosis and baseline attention and working memory composite score as covariates, or for functional outcome, ANCOVA with diagnosis as a covariate.

${ }^{*} p \leqslant 0.05,{ }^{* *} p \leqslant 0.01$.

demonstrating that functional improvements are mediated by memory improvements (Wykes et al. 2007; Fiszdon et al. 2008), although executive functioning improvements have also been shown to predict functional gains following CR (Reeder et al. 2004, 2006; Wykes et al. 2012). The failure to find a relationship between executive functioning change and functional improvement was not entirely surprising given that executive functioning did not respond to $C R$ in the current study. Nonetheless, the current results suggest that delayed learning and memory potentially mediates psychosocial gains, although this requires further validation as our results were only significant at a trend to marginal level, and cognitive functioning improvements may require more time to generalize to real-world functioning.

In addition to neuropsychological functioning, several other mechanisms may explain social and role functioning improvements attributable to CR. Social functioning improvements may be mediated by aspects of social cognition, either wholly (Addington et al. 2010; Schmidt et al. 2011) or partly (Hoe et al. 2012). Thus, cognitive functioning may be a necessary, but insufficient, condition for functional improvement. With regard to role functioning, self-efficacy, job opportunities and social networks, to name a few, may moderate functional change over and above cognition. For instance, as a result of the current CR treatment, participants' self-efficacy beliefs regarding their own abilities may be strengthened in response to observed improvements on training tasks and, as a result, stimulate their attempts to seek out employment or return to study. That is not to say that cognitive functioning plays no part in role functioning. Indeed, it is difficult to imagine how someone can hold down a moderately demanding job or area of study with clinically significant cognitive impairments. Instead, cognitive improvements may influence role functioning once a patient has returned to a higher level of functioning and is expected to maintain those roles, consistent with evidence that neurocognition is associated with job tenure, but not job attainment (Gold et al. 2002). Thus, targeting self-efficacy may prove crucial in improving occupational or academic functioning in the initial stages of illness (Caprara et al. 2004). Taken together, factors other than neuropsychological functioning, such as social cognition and self-efficacy, may be crucial rate-limiting factors in the translation of cognitive gains into the real world. Furthermore, these factors could potentially account for a significant portion of the $79 \%$ of functional improvement currently left unexplained.

The current study also demonstrated that cognitive and functional improvements were detected even while controlling for the effects of diagnosis. This is consistent with previous findings of CR's crossdiagnostic utility (Lewandowski et al. 2011), and provides additional support for the need to expand the application of $\mathrm{CR}$ into other psychiatric populations with demonstrable neuropsychological dysfunction.

\section{Limitations and future directions}

There were several limitations to the current study. The lack of blinded assessments may have biased the clinical and neuropsychological results, although 
previous findings have found negligible effects of methodological rigour on treatment effect (Wykes et al. 2011). Similarly, current practice in conducting clinical trials favours the use of 'active' controls over the use of 'passive' controls. The rationale is that the use of active controls can account for non-specific therapistrelated effects, such as demand characteristics. However, as with blindedness, previous meta-analytic research has found minimal effect for control type on the effect size of improvements (McGurk et al. 2007; Lewandowski et al. 2011). Lastly, in terms of sample size, the current study was also relatively modest and may have been underpowered to detect small to moderate effects typical of CR studies. The sample size, however, was not incidental, and is reflective of the difficulty in implementing a neuropsychological intervention in youth cohorts, where engagement may be particularly difficult and drop-outs not uncommon. To this end, future studies may benefit from incorporating motivational interviewing techniques into CR programmes to help facilitate engagement and, as a result, adherence (Markland et al. 2005). Future studies should also examine the factors that predict treatment response, which was not currently conducted because of the restrictive sample size. The modest sample size also meant that more sophisticated modelling of the relationships between neuropsychological variables and functional improvements was not feasible (see Wykes et al. 2012 for an example of this type of analysis).

\section{Summary}

The current study is the first to demonstrate the effectiveness of CR in clinically stable out-patients diagnosed with a solely first episode of major depression or psychosis. Improvements were detected in both immediate learning and memory and psychosocial functioning. Improvements in delayed learning and memory contributed to psychosocial gains at a trend level, over and above the functional benefits of treatment. We propose that other factors, such as social cognition and self-efficacy, may also mediate the effects between cognitive and functional gains, and should be further explored. Future studies should also follow up patients longitudinally to determine the baseline predictors of functional improvement, to allow enough time for cognitive gains to translate into the real world, and to determine the durability of improvements. Despite several limitations in the current study design, it provides evidence of the potential that $\mathrm{CR}$ has as a potent early and targeted intervention strategy for those presenting with severe mental illness. Future studies need to examine this cohort further under more rigorously controlled conditions to provide more cogent evidence that $\mathrm{CR}$ should be incorporated into the standard treatment of psychiatric illnesses.

\section{Acknowledgements}

We thank C. Chudleigh for help with facilitating treatment, K. Diamond for providing resources and clinical supervision, and M. Kaur for her administrative assistance. We also thank all the clinicians who made referrals to the current research programme without whom the current study would not have been possible.

This research was supported by a National Health and Medical Research Council (NHMRC) Program Grant (No. 350241) and an NHMRC Australia Fellowship awarded (No. 511921) to I.B.H. S.LN. was funded by an NHMRC Clinical Research Fellowship (No. 402864).

\section{Declaration of Interest}

I.B.H. has led projects for health professionals and the community supported by governmental, community agency, and drug industry partners (Wyeth, Eli Lilly, Servier, Pfizer, AstraZeneca) for the identification and management of depression and anxiety. He has served on advisory boards convened by the drug industry in relation to specific antidepressants, including nefazodone, duloxetine, and desvenlafaxine, and has participated in a multicenter clinical trial of agomelatine effects on sleep architecture in depression. He has participated in Servier-sponsored educational programs related to circadian-based therapies. D.F.H. has previously received honoraria for educational seminars from Janssen-Cilag. M.A.R.H. has received financial support from Eli Lilly for a multisite trial of cognitive remediation in psychosis, and is a coinvestigator in an Australian Rotary-funded project investigating the synergistic effects of cognitive remediation and vocational training in psychosis. She was also a co-investigator in a drug trial with Novartis Pharmaceutical who sponsored overseas travel in 2011, and was also involved in NHMRC-funded trials in psychosis.

\section{References}

Addington J, Girard TA, Christensen BK, Addington D (2010). Social cognition mediates illness-related and cognitive influences on social function in patients with schizophrenia-spectrum disorders. Journal of Psychiatry and Neuroscience 35, 49-54.

Amminger G, Edwards J, Brewer W, Harrigan S, McGorry P (2002). Duration of untreated psychosis and cognitive 
deterioration in first-episode schizophrenia. Schizophrenia Research 54, 223-230.

APA (2000). Diagnostic and Statistical Manual of Mental Disorders, 4th edn, text revision (DSM-IV-TR).

American Psychiatric Association: Washington, DC.

Bickel WK, Yi R, Landes RD, Hill PF, Baxter C (2011). Remember the future: working memory training decreases delay discounting among stimulant addicts. Biological Psychiatry 69, 260-265.

Birchwood M, Smith J, Cochrane R, Wetton S, Copestake S (1990). The Social Functioning Scale. The development and validation of a new scale of social adjustment for use in family intervention programmes with schizophrenic patients. British Journal of Psychiatry 157, 853-859.

Breitborde NJK, Moreno FA, Mai-Dixon N, Peterson R, Durst L, Berstein B, Byreddy S, McFarlane WR (2011). Multifamily group psychoeducation and cognitive remediation for first-episode psychosis: a randomized controlled trial. BMC Psychiatry 11, 9.

Brekke JS, Hoe M, Green MF (2009). Neurocognitive change, functional change and service intensity during community-based psychosocial rehabilitation for schizophrenia. Psychological Medicine 39, 1637-1647.

Buhlmann U, Deckersbach T, Engelhard I, Cook LM, Rauch SL, Kathmann N, Wilhelm S, Savage CR (2006). Cognitive retraining for organizational impairment in obsessive-compulsive disorder. Psychiatry Research 144, 109-116.

Caprara GV, Barbaranelli C, Pastorelli C, Cervone D (2004). The contribution of self-efficacy beliefs to psychosocial outcomes in adolescence: predicting beyond global dispositional tendencies. Personality and Individual Differences 37, 751-763.

Choi J, Medalia A (2005). Factors associated with a positive response to cognitive remediation in a community psychiatric sample. Psychiatric Services 56, 602-604.

Cohen BD (1956). Motivation and performance in schizophrenia. Journal of Abnormal and Social Psychology 52, 186-190.

Cohen J (1988). Statistical Power Analysis for the Behavioral Sciences, 2nd edn. Lawrence Erlbaum: Mahwah, NJ.

Corwin J, Bylsma FW (1993). Psychological examination of traumatic encephalopathy. Clinical Neuropsychologist 7, 3-21.

Crawford JR, Stewart LE, Moore JW (1989). Demonstration of savings on the AVLT and development of a parallel form. Journal of Clinical and Experimental Neuropsychology 11, 975-981.

Deckersbach T, Nierenberg AA, Kessler R, Lund HG Ametrano RM, Sachs G, Rauch SL, Dougherty D (2010). Cognitive rehabilitation for bipolar disorder: an open trial for employed patients with residual depressive symptoms. CNS Neuroscience and Therapeutics 16, 298-307.

Dickinson D, Tenhula W, Morris S, Brown C, Peer J, Spencer K, Li L, Gold JM, Bellack AS (2010). A randomized, controlled trial of computer-assisted cognitive remediation for schizophrenia. American Journal of Psychiatry 167, 170-180.
Eack SM, Greenwald DP, Hogarty SS, Cooley SJ, DiBarry AL, Montrose DM, Keshavan MS (2009). Cognitive enhacement therapy for early-course schizophrenia: effects of a two-year randomized controlled trial. Psychiatric Services 60, 1468-1476.

Eack SM, Hogarty GE, Cho RY, Prasad KMR, Greenwald DP, Hogarty SS, Keshavan MS (2010). Neuroprotective effects of cognitive enhancement therapy against gray matter loss in early schizophrenia. Archives of General Psychiatry 67, 674-682.

Elgamal S, Mckinnon MC, Ramakrishnan K, Joffe RT, MacQueen G (2007). Successful computer-assisted cognitive remediation therapy in patients with unipolar depression: a proof of principle study. Psychological Medicine 37, 1229-1238.

Fiszdon JM, Choi J, Goulet J, Bell MD (2008). Temporal relationship between change in cognition and change in functioning in schizophrenia. Schizophrenia Research 105, 105-113.

Franzen MD, Paul DS, Price G (1990). Alternate form reliability of Trails A, B, C, and D. Paper presented at the Ninth Annual Convention of the National Academy of Neuropsychology, Reno, NY.

Fusar-Poli P, Deste G, Smieskova R, Barlati S, Yung A, Howes O, Stieglitz R-D, Vita A, McGuire P, Borgwardt S (2012). Cognitive functioning in prodromal psychosis: a meta-analysis. Archives of General Psychiatry 69, 562-571.

Gaynor K, Dooley B, Lawlor E, Lawoyin L, O'Callaghan E (2009). Cognitive deterioration and duration of untreated psychosis. Early Intervention in Psychiatry 3, 157-160.

Gold JM, Goldberg RW, McNary SW, Dixon LB, Lehman AF (2002). Cognitive correlates of job tenure among patients with severe mental illness. American Journal of Psychiatry 159, 1395-1402.

Goldberg TE, Goldman RS, Burdick KE, Malhotra AK, Lencz T, Patel RC, Woerner MG, Schooler NR, Kane JM, Robinson DG (2007). Cognitive improvement after treatment with second-generation antipsychotic medications in first-episode schizophrenia: is it a practice effect? Archives of General Psychiatry 64, 1115-1122.

Goldberg TE, Keefe RSE, Goldman RS, Robinson DG, Harvey PD (2010). Circumstances under which practice does not make perfect: a review of the practice effect literature in schizophrenia and its relevance to clinical treatment studies. Neuropsychopharmacology 35, 1053-1062.

Green MF, Kern RS, Heaton RK (2004). Longitudinal studies of cognition and functional outcome in schizophrenia: implications for MATRICS. Schizophrenia Research 72, 41-51.

Gupta M, Holshausen K, Bowie CR (2011). Cognitive remediation in early episode and chronic outpatients with schizophrenia: who has more to gain? In Cognitive Remediation in Psychiatry, New York City, NY.

Hamilton M (1960). A rating scale for depression. Journal of Neurology, Neurosurgery, and Psychiatry 23, 56-62.

Hetrick SE, Parker AG, Hickie IB, Purcell R, Yung AR, McGorry PD (2008). Early identification and intervention in depressive disorders: towards a clinical staging model. Psychotherapy and Psychosomatics 77, 263-270. 
Hickie I, Scott E, Hermens D, Naismith S, Guastella A, Kaur M, Sidis A, Whitwell B, Glozier N, Davenport T, Pantelis C, Wood S, McGorry P (2012). Applying clinical staging to young people who present for mental health care. Early Intervention in Psychiatry. Published online: 5 June 2012. doi:10.1111/j.1751-7893.2012.00366.x.

Hoe M, Nakagami E, Green MF, Brekke JS (2012). The causal relationships between neurocognition, social cognition and functional outcome over time in schizophrenia: a latent difference score approach. Psychological Medicine. Published online: 5 April 2012. doi:10.1017/S0033291712000578.

Hubley AM, Tremblay D (2002). Comparability of total score performance on the Rey-Osterrieth Complex Figure and a modified Taylor Complex Figure. Journal of Clinical and Experimental Neuropsychology 24, 370-382.

Jaeger J, Berns S, Uzelac S, Davis-Conway S (2006). Neurocognitive deficits and disability in major depressive disorder. Psychiatry Research 145, 39-48.

Kahn RS, Fleischhacker WW, Boter H, Davidson M, Vergouwe Y, Keet IPM, Gheorghe MD, Rybakowski JK, Galderisi S, Libiger J, Hummer M, Dollfus S, Lopez-Ibor JJ, Hranov LG, Gaebel W, Peuskens J, Lindefors N, Riecher-Rossler A, Grobbee DE; EUFEST study group (2008). Effectiveness of antipsychotic drugs in first-episode schizophrenia and schizophreniform disorder: an open randomised clinical trial. Lancet 371, 1085-1097.

Kane JM, Leucht S, Carpenter D, Docherty JP; Expert Consensus Panel for Optimizing Pharmacologic Treatment of Psychotic Disorders (2003). The expert consensus guideline series. Optimizing pharmacologic treatment of psychotic disorders. Introduction: methods, commentary, and summary. Journal of Clinical Psychiatry 64 (Suppl. 12), 5-19.

Keefe RSE, Bilder RM, Davis SM, Harvey PD, Palmer BW, Gold JM, Meltzer HY, Green MF, Capuano G, Stroup TS, McEvoy JP, Swartz MS, Rosenheck RA, Perkins DO, Davis CE, Hsiao JK, Lieberman JA; CATIE Investigators (2007). Neurocognitive effects of antipsychotic medications in patients with chronic schizophrenia in the CATIE trial. Archives of General Psychiatry 64, 633-647.

Lappin JM, Morgan K, Morgan C, Hutchison G, Chitnis X, Suckling J, Fearon P, McGuire PK, Jones PB, Leff J, Murray RM, Dazzan P (2006). Gray matter abnormalities associated with duration of untreated psychosis. Schizophrenia Research 83, 145-153.

Lappin JM, Morgan KD, Morgan C, Dazzan P, Reichenberg A, Zanelli JW, Fearon P, Jones PB, Lloyd T, Tarrant J, Farrant A, Leff J, Murray RM (2007). Duration of untreated psychosis and neuropsychological function in first episode psychosis. Schizophrenia Research 95, 103-110.

Lee RSC, Hermens DF, Porter MA, Redoblado-Hodge MA (2012). A meta-analysis of cognitive deficits in first-episode major depressive disorder. Journal of Affective Disorders 140, 113-124.

Leeson VC, Sharma P, Harrison M, Ron MA, Barnes TRE, Joyce E (2011). IQ trajectory, cognitive reserve, and clinical outcome following a first episode of psychosis: a 3-year longitudinal study. Schizophrenia Bulletin 37, 768-777.
Lewandowski KE, Eack SM, Hogarty SS, Greenwald DP, Keshavan MS (2011). Is cognitive enhancement therapy equally effective for patients with schizophrenia and schizoaffective disorder? Schizophrenia Research 125, 291-294.

Lezak MD, Howieson DB, Bigler ED, Tranel E (2012). Neuropsychological Assessment, 5th edn. Oxford University Press: New York.

Lynch D, Laws K, McKenna P (2010). Cognitive behavioural therapy for major psychiatric disorder: does it really work? A meta-analytical review of well-controlled trials. Psychological Medicine 40, 9-24.

Majer M, Ising M, Kunzel H, Binder E, Holsboer F, Modell S, Zihl J (2004). Impaired divided attention predicts delayed response and risk to relapse in subjects with depressive disorders. Psychological Medicine 34, 1453-1463.

Malla AK, Bodnar M, Joober R, Lepage M (2011). Duration of untreated psychosis is associated with orbital-frontal grey matter volume reductions in first episode psychosis. Schizophrenia Research 125, 13-20.

Markland D, Ryan RM, Tobin VJ, Rollnick S (2005). Motivational interviewing and self-determination theory. Journal of Social and Clinical Psychology 24, 811-831.

McGorry PD, Hickie IB, Yung AR, Pantelis C, Jackson HJ (2006). Clinical staging of psychiatric disorders: a heuristic framework for choosing earlier, safer and more effective interventions. Australian and New Zealand Journal of Psychiatry 40, 616-622.

McGurk PDS, Twamley PDE, Sitzer PDD, McHugo PDG, Mueser PDK (2007). A meta-analysis of cognitive remediation in schizophrenia. American Journal of Psychiatry 164, 1791-1802.

Medalia A, Choi J (2009). Cognitive remediation in schizophrenia. Neuropsychology Review 19, 353-364.

Medalia A, Freilich B (2008). The Neuropsychological Educational Approach to Cognitive Remediation (NEAR) model: practice principles and outcome studies. American Journal of Psychiatric Rehabilitation 11, 123-143.

Medalia A, Revheim N, Herlands T (2002). Remediation of Cognitive Deficits in Psychiatric Patients: A Clinician's Manual. Montefiore Medical Center Press: New York City, NY.

Medalia A, Saperstein A (2011). The role of motivation for treatment success. Schizophrenia Bulletin 37, S122-S128.

Medalia A, Thysen J (2008). Insight into neurocognitive dysfunction in schizophrenia. Schizophrenia Bulletin 34, 1221-1230.

Mesholam-Gately RI, Giuliano AJ, Goff KP, Faraone SV, Seidman LJ (2009). Neurocognition in first-episode schizophrenia: a meta-analytic review. Neuropsychology 23, 315-336.

Meyers J, Meyers K (1995). Rey Complex Figure Test and Recognition Trial: Professional Manual. Psychological Assessment Resources: Odessa, FL.

Meyers J, Meyers K (1996). Rey Complex Figure Test and Recognition Trial: Supplemental Norms for Children and Adolescents. Psychological Assessment Resources:

Odessa, FL. 
Millan MJ, Agid Y, Brüne M, Bullmore ET, Carter CS, Clayton NS, Connor R, Davis S, Deakin B, DeRubeis RJ, Dubois, B, Geyer MA, Goodwin GM, Gorwood P, Jay TMJ, Joëls M, Mansuy IM, Meyer-Lindenberg A, Murphy D, Rolls E, Saletu B, Spedding M, Sweeney J, Whittington M, Young LJ (2012). Cognitive dysfunction in psychiatric disorders: characteristics, causes and the quest for improved therapy. Nature Reviews Drug Discovery 11, 141-168.

Minzenberg MJ, Poole JH, Benton C, Vinogradov S (2004). Association of anticholinergic load with impairment of complex attention and memory in schizophrenia. American Journal of Psychiatry 161, 116-124.

Naismith SL, Diamond K, Carter PE, Norrie L, RedobladoHodge MA, Lewis SJG, Hickie IB (2011). Enhancing memory in late-life depression: the effects of a combined psychoeducation and cognitive training program. American Journal of Geriatric Psychiatry 19, 240-248.

Naismith SL, Redoblado-Hodge MA, Hermens DF, Carter PE, Scott EM, Hickie IB (2010a). Cognitive training improves cognitive and psychosocial functioning in a mixed psychiatric outpatient sample. Journal of Cognitive Rehabilitation 28, 4-10.

Naismith SL, Redoblado-Hodge MA, Lewis SJG, Scott EM, Hickie IB (2010b). Cognitive training in affective disorders improves memory: a preliminary study using the NEAR approach. Journal of Affective Disorders 121, 258-262.

Redoblado-Hodge MA, Siciliano D, Withey P, Moss B, Moore G, Judd G, Shores EA, Harris A (2010). A randomized controlled trial of cognitive remediation in schizophrenia. Schizophrenia Bulletin 36, 419-427.

Reeder C, Newtown E, Frangou S, Wykes T (2004). Which executive skills should we target to affect social functioning and symptom change? A study of a cognitive remediation therapy program. Schizophrenia Bulletin 36, 87-100.

Reeder C, Smedley N, Butt K, Bogner D, Wykes T (2006). Cognitive predictors of social functioning improvements following cognitive remediation for schizophrenia. Schizophrenia Bulletin 32, S123-S131.

Reitan RM, Wolfson D (1985). The Halstead-Reitan Neuropsychological Test Battery: Therapy and Clinical Interpretation. Neuropsychological Press: Tucson, AZ.

Rickert P, Senior G (1998). WMS-III list learning test and the Rey auditory verbal learning test: comparisons and Australian normative data. In 4th Annual Conference of the College of Clinical Neuropsychologists, Loren, Victoria, Australia.

Ruzanna Z, Marhani M, Parveen K, Cheah YC (2010). Does psychoeducation improve insight of patients with schizophrenia? Malaysian Journal of Psychiatry 19, $27-40$.

Salthouse TA (2012). Robust cognitive change. Journal of the International Neuropsychological Society 18, 1-8.

Schatzberg AF, Posener JA, DeBattista C, Kalehzan BM, Rothschild AJ, Shear PK (2000). Neuropsychological deficits in psychotic versus nonpsychotic major depression and no mental illness. American Journal of Psychiatry 157, 1095-1100.
Schmidt SJ, Mueller DR, Roder V (2011). Social cognition as a mediator variable between neurocognition and functional outcome in schizophrenia: empirical review and new results by structural equation modeling. Schizophrenia Bulletin 37, S41-S54.

Schretlen DJ, Munro CA, Anthony JC, Pearlson GD (2003). Examining the range of normal intraindividual variability in neuropsychological test performance. Journal of the International Neuropsychological Society 9 , 864-870.

Scott E, Hermens D, Glozier N, Naismith S, Guastella A, Hickie I (2012). Targeted primary care-based mental health services for young Australians. Medical Journal of Australia 196, 136-140.

Scott E, Naismith S, Whitwell B, Hamilton B, Chudleigh C, Hickie I (2009). Delivering youth-specific mental health services: the advantages of a collaborative, multidisciplinary system. Australasian Psychiatry 17, 189-194.

Sheline YI, Gado MH, Kraemer HC (2003). Untreated depression and hippocampal volume loss. American Journal of Psychiatry 160, 1516-1518.

Spreen O, Benton AL (1977). Neurosensory Center Comprehensive Examination for Aphasia. Neuropsychology Laboratory, University of Victoria: Victoria, BC.

Taylor EM (1959). Psychological Appraisal of Children with Cerebral Deficits. Harvard University Press: Cambridge, MA.

Tombaugh TN, Kozak J, Rees L (1999). Normative data stratified by age and education for two measures of verbal fluency: FAS and animal naming. Archives of Clinical Neuropsychology 14, 167-177.

Tombaugh TN, Rees L, McIntyre N (1996). Normative data for the trail making test. In A Compendium of Neuropsychological Tests: Administration, Norms and Commentary, 2nd edn (ed. O. Spreen and E. Strauss), p. 540. Oxford University Press: New York.

Ueland T, Rund BR (2004). A controlled randomized treatment study: the effects of a cognitive remediation program on adolescents with early onset psychosis. Acta Psychiatrica Scandinavica 109, 70-74.

Ueland T, Rund BR (2005). Cognitive remediation for adolescents with early onset psychosis: a 1-year follow-up study. Acta Psychiatrica Scandinavica 111, 193-201.

Ventura J, Green MF, Shaner A, Liberman RP (1993). Training and quality assurance with the Brief Psychiatric Rating Scale: 'The drift busters'. International Journal of Methods in Psychiatric Research 3, 221-224.

Vesterager L, Christensen TØ, Olsen BB, Krarup G, Forchhammer HB, Melau M, Gluud C, Nordentoft M (2011). Cognitive training plus a comprehensive psychosocial programme (OPUS) versus the comprehensive psychosocial programme alone for patients with first-episode schizophrenia (the NEUROCOM trial): a study protocol for a centrally randomised, observer-blinded multi-centre clinical trial. Trials 12, 35.

Wagner BR (1968). The training of attending and abstracting responses in chronic schizophrenia. Journal of Experimental Research in Personality 3, 77-88. 
Wechsler DS (1997a). Wechsler Adult Intelligence Scale - Third Edition (WAIS-III). The Psychological Corporation: San Antonio, TX.

Wechsler DS (1997b). Wechsler Memory Scale - Third Edition (WMS-III). The Psychological Corporation: San Antonio, TX.

Wechsler DS (2001). Wechsler Test of Adult Reading. The Psychological Corporation: San Antonio, TX.

Withall A, Harris L, Cumming S (2009). The relationship between cognitive function and clinical and functional outcomes in major depressive disorder. Psychological Medicine 39, 393-402.

Wood L, Al-Khairulla H, Lask B (2011). Group cognitive remediation therapy for adolescents with anorexia nervosa. Clinical Child Psychology and Psychiatry 16, 225-231.

Wykes T, Huddy V, Cellard C, McGurk SR, Czobor P (2011). A meta-analysis of cognitive remediation for schizophrenia: methodology and effect sizes. American Journal of Psychiatry 168, 472-485.
Wykes T, Newton E, Landau S, Rice C, Thompson N, Frangou S (2007). Cognitive remediation therapy (CRT) for young early onset patients with schizophrenia: an exploratory randomized controlled trial. Schizophrenia Research 94, 221-230.

Wykes T, Reeder C, Huddy V, Taylor R, Wood H, Ghirasim N, Kontis D, Landau S (2012).

Developing models of how cognitive improvements change functioning: mediation, moderation and moderated mediation. Schizophrenia Research 138, 88-93.

Wykes T, Reeder C, Landau S, Matthiasson P, Haworth E, Hutchinson C (2009). Does age matter? Effects of cognitive rehabilitation across the age span. Schizophrenia Research 113, 252-258.

Yen C-F, Chen C-C, Lee Y, Tang T-C, Ko C-H, Yen J-Y (2005). Insight and correlates among outpatients with depressive disorders. Comprehensive Psychiatry 46, 384-389. 